\title{
Loss of Zbtb32 in NOD mice does not significantly alter T cell
}

\section{responses. [version 1; peer review: 2 approved]}

\author{
William D. Coley1, Yongge Zhao (iD1, Charles J. Benck1, Yi Liu1, \\ Chie Hotta-Iwamura1, M. Jubayer Rahman'1, Kristin V Tarbell(iD1,2
}

${ }^{1}$ Immune Tolerance Section, National Institute of Diabetes and Digestive and Kidney Diseases, National Institutes of Health,
Bethesda, MD, 20892, USA
2Department of Inflammation and Oncology, Amgen, Inc, South San Francisco, CA, USA

V1 First published: 14 Mar 2018, 7:318

https://doi.org/10.12688/f1000research.13864.1

Latest published: 05 Nov 2018, 7:318

https://doi.org/10.12688/f1000research.13864.2

\section{Abstract}

Background: We previously identified the transcriptional regulator Zbtb32 as a factor that can promote $T$ cell tolerance in the Non-Obese Diabetic (NOD) mouse, a model of Type 1 diabetes. Antigen targeted to DCIR2 $^{+}$dendritic cells (DCs) in vivo inhibited both diabetes and effector T cell expansion in NOD mice. Furthermore, Zbtb32 was preferentially induced in autoreactive CD4 T cells stimulated by these tolerogenic DCIR2 ${ }^{+}$DCs, and overexpression of Zbtb32 in islet-specific $T$ cells inhibited the diabetes development by limiting $T$ cell proliferation and cytokine production.

Methods: To further understand the role of Zbtb32 in T cell tolerance induction, we have now used CRISPR to target the Zbtb32 gene for deletion directly in NOD mice and characterized the mutant mice. We hypothesized that the systemic loss of Zbtb32 in NOD mice would lead to increased $T$ cell activation and increased diabetes pathogenesis.

Results: Although NOD.Zbtb32/-- male NOD mice showed a trend towards increased diabetes incidence compared to littermate controls, the difference was not significant. Furthermore, no significant alteration in lymphocyte number or function was observed. Importantly, in vitro stimulation of lymphocytes from NOD.Zbtb32-/mice did not produce the expected hypersensitive phenotype observed in other genetic strains, potentially due to compensation by homologous genes.

Conclusions: The loss of Zbtb32 in the NOD background does not result in the expected $\mathrm{T}$ cell activation phenotype.

Keywords

Zbtb32, ROG, NOD, diabetes, CRISPR, CRISPR/Cas9

\section{Open Peer Review}

Approval Status

1 2

version 2

(revision)

05 Nov 2018

version 1

14 Mar 2018

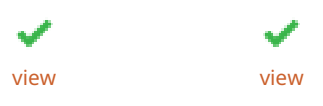

1. Hubert M. Tse , University of Alabama at Birmingham, Birmingham, USA

2. Ivan C. Gerling ID, University of Tennessee Health Science Center, Memphis, USA

Any reports and responses or comments on the article can be found at the end of the article. 


\section{Corresponding author: Kristin V Tarbell (ktarbell@amgen.com)}

Author roles: Coley WD: Data Curation, Formal Analysis, Investigation, Methodology, Validation, Visualization, Writing - Original Draft Preparation; Zhao Y: Data Curation, Investigation, Methodology, Validation; Benck CJ: Data Curation, Investigation; Liu Y: Data Curation, Investigation; Hotta-Iwamura C: Investigation, Writing - Review \& Editing; Rahman MJ: Investigation, Writing - Review \& Editing;

Tarbell KV: Conceptualization, Funding Acquisition, Project Administration, Supervision, Writing - Review \& Editing

Competing interests: Kristin Tarbell is currently an employee of Amgen; all work described here was performed at NIDDK and has received no financial support from Amgen.

Grant information: This work was supported by the Intramural Research Program of the National Institute of Diabetes and Digestive and Kidney Diseases, Project \# 1ZIADK075065-06.

The funders had no role in study design, data collection and analysis, decision to publish, or preparation of the manuscript.

Copyright: (c) 2018 Coley WD et al. This is an open access article distributed under the terms of the Creative Commons Attribution License, which permits unrestricted use, distribution, and reproduction in any medium, provided the original work is properly cited. Data associated with the article are available under the terms of the Creative Commons Zero "No rights reserved" data waiver (CC0 1.0 Public domain dedication).

How to cite this article: Coley WD, Zhao Y, Benck CJ et al. Loss of Zbtb32 in NOD mice does not significantly alter T cell responses. [version 1; peer review: 2 approved] F1000Research 2018, 7:318 https://doi.org/10.12688/f1000research.13864.1

First published: 14 Mar 2018, 7:318 https://doi.org/10.12688/f1000research.13864.1 


\section{Introduction}

Although some autoimmune diseases can be managed by the use of immunosuppressive drugs, current treatment options for individuals with Type 1 diabetes (T1D) are largely limited to controlling the disease symptoms instead of addressing the underlying autoimmune assault ${ }^{1}$. Reestablishing immune tolerance to the targeted self-antigens could provide more specific and durable treatment options ${ }^{2}$. The Non-Obese Diabetic (NOD) mouse strain spontaneously develops autoimmune diabetes, and can be used to identify how tolerance is defective in chronic autoimmune environments or to find potential therapies that can overcome these defects ${ }^{3,4}$.

Previously, we targeted self antigens to specific dendritic cell (DC) subsets by using chimeric antibodies that recognize antigen uptake receptors (either DEC205 for $\mathrm{cDC}^{\mathrm{s}} \mathrm{s}^{5}$ or DCIR2 for cDC2s) with the relevant self peptide covalently attached ${ }^{6}$. The entire antibody is internalized and the antigenic self peptide is then processed and presented on MHC class II. This allowed identification of DC subsets able to induce tolerance against $\beta$-islet antigens within the context of chronic autoimmunity found in NOD mice. Using this approach, we demonstrated that selfantigen presentation by DCIR2 ${ }^{+}$DCs but not DEC $205^{+}$DCs could promote self-tolerance via increased apoptosis and decreased effector functions in islet-specific CD4 $\mathrm{T}$ cells ${ }^{6}$. A gene expression analysis of the affected autoreactive $\mathrm{T}$ cells showed increased early expression of Zbtb32 in T cells stimulated by DCIR2 ${ }^{+}$DCs. In addition, transient overexpression of Zbtb32 in islet-specific CD4 $\mathrm{T}$ cells delayed diabetes development, and decreased both proliferation and IFN $\gamma$ production in isletspecific $\mathrm{CD}^{+} \mathrm{T}$ cells ${ }^{6}$. Together these studies suggest $\mathrm{T}$ cell expression of Zbtb32 plays a role in tolerance induction in NOD mice, and could be a target for treatment.

The Zbtb32 gene (also known as ROG or PLZP) was first identified as a homologue of the leukemia oncogene PLZF (Zbtb16) ${ }^{7}$ Z Zbtb32 was then shown to act as a transcriptional repressor of GATA-3 ${ }^{8,9}$. Since GATA-3 regulates thymocyte development and $\mathrm{T}_{\mathrm{H}} 2$ differentiation, Zbtb32 knockout mice were produced to test if Zbtb32 played a role in modulating lymphocyte development and response to stimuli. In three genetic backgrounds (129/SV, C57B16, and BALB/c), the homozygous loss of Zbtb32 significantly altered $\mathrm{T}$ cell responses resulting in increased proliferation, increased cytokine production, and hypersensitive responses to inflammatory stimuli ${ }^{10-13}$. NK cells and B cells from C57B16 mice lacking Zbtb32 similarly displayed hyperproliferation and increased effector functions ${ }^{14,15}$. Therefore, data from these knockout strains show that Zbtb32 functions as a brake for lymphocyte activation and differentiation, and is consistent with our data from transient overexpression of Zbtb32 in T cells.

To better understand the role of Z Ztb32 for $\mathrm{T}$ cell tolerance in autoimmune NOD mice, we introduced a targeted deletion using CRISPR/CAS9 techniques. The creation of mutant NOD strains has been severely limited by the lack of a robust ES line, necessitating backcrossing knockouts made in other genetic backgrounds onto the NOD background ${ }^{16,17}$. Because the region surrounding the knockout locus will retain alleles from the original strain, this can confound interpretation of such mice. NOD mice carry dozens of genetic susceptibility loci that contribute to the onset of T1D and some of those linked alleles could alter diabetes susceptibility or immune phenotype of any new mutant strain $^{18}$. These issues can be avoided by using CRISPR/CAS9 technology to directly edit DNA in NOD embryos, an approach utilized only very recently in the NOD $\operatorname{strain}^{19}$. For the present study, we deleted a portion of exon 2 to cause a frameshift mutation in the Zbtb32 gene, and validated the loss of the Zbtb32 protein in our colony of NOD.Zbtb32 $2^{--}$ mice. These mice were used to test our hypothesis that the transcription repressor Zbtb32 plays a critical role in the inhibition of T-cell mediated autoimmune T1D. Surprisingly, T cells from NOD.Zbtb32 $2^{-1-}$ mice were not hyperreactive as would have been expected based on both our prior overexpression data and knockout mice in other strains. Although male NOD.Zbtb32-mice showed a trend of increased diabetes incidence compared to littermate controls, the difference was not significant, and no significant difference in either time of onset or overall incidence was observed in female NOD.Zbtb32 $32^{-/}$mice. Overall, most of our experiments suggested mild phenotypic changes perhaps as a result of either compensation by other family members or by effects on multiple cell types that is different on the NOD genetic background.

\section{Methods}

Mice

Non-Obese Diabetic mice (NOD, JAX \#001976) were initially obtained from The Jackson Laboratory, Bar Harbor ME, and bred in the facility at NIH. Additional NOD females were regularly delivered every two weeks to compensate for the loss of breeders due to diabetes in the wildtype NOD colony. Approximately 630 NOD.Zbtb32-/ mice (about 90 litters with an average liter size of 7) were bred during the characterization the mutant strain. All mice were housed in a specific pathogen free vivarium with a $12 \mathrm{~h}$ on/12 h off light cycle (6 am on and $6 \mathrm{pm}$ off). The care, use, and disposition of all mice used in this study were reviewed and approved (protocol K024-DEOB-16) by the Institutional Animal Care and Use Committee of the NIDDK, NIH. Diabetes was monitored and mice were considered diabetic on the first of two blood glucose level measurements above $250 \mathrm{mg} / \mathrm{dl}$.

\section{Generation of knockout}

The NOD.Zbtb32 $2^{--}$genetic alteration was carried out as follows: NOD female mice (6-8 weeks old) were super ovulated and mated overnight with NOD male mice ( $>8$ weeks old). Zygotes were harvested from the ampullae of super ovulated females and were placed in KSOM medium (Millipore, Billerica MA) before microinjection. Microinjection was performed in M2 medium (Sigma, St Louis, MO) using a micromanipulator (Narishige) and microscope (Nikon). The second exon of the Zbtb32 gene was targeted using the two following RNA guide sequences; 5'-UACAG UUAGC GGCUA GACUC-3' and 5'-CAAUC AUGGA UCCCC CAUUG-3'. Binding sites for single guide RNA (sg RNA) are indicated in Figure 1A. The modified Cas9n enzyme with nickase activity (System Biosciences) and sgRNA were 


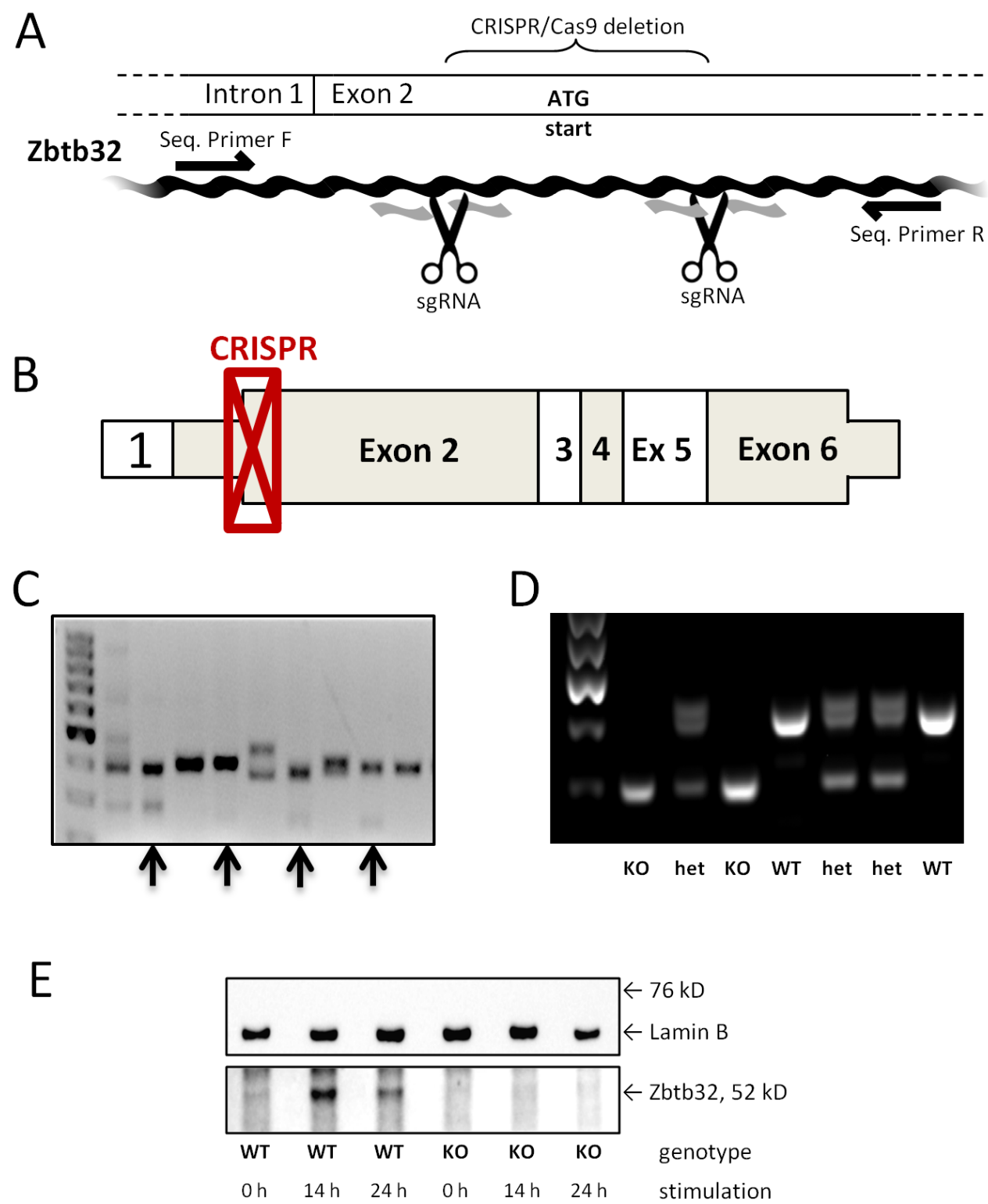

Figure 1. Confirmation of CRISPR-mediated knockout of Zbtb32. The CRISPR/Cas9 technique was used to target exon 2 of the Zbtb32 gene directly in NOD mice. A portion of the Zbtb32 gene was deleted and a frameshift introduced in NOD mice using the CRISPR/Cas9 technique, as illustrated here $(\mathbf{A})$. The scissors represent the location of cutting based on sgRNA binding and black arrows indicate binding sites for the standard primers, which were used for both sequencing and genotyping. The location of the deletion maps onto the beginning of exon2 of the wildtype mRNA (B). Non-coding portions are shown as thinner than the coding portions. The CRISPR/Cas9-treated embryos develop into mice with genetic mosaicism of the Zbtb32 gene in the F0 generation. Four genetically heterogeneous females (indicated with black arrows) were examined further before one mutant allele was chosen to establish the NOD.Zbtb32 $\%$ colony (C). The targeted deletion of Zbtb32 removed 146 bp from exon 2 as shown by genetic screening of knockout, heterozygous, and wildtype animals in the F2 generation (D). The loss of the Zbtb32 protein after CRISPR-mediated deletion was confirmed by Western blotting extracts from stimulated CD4+ splenocytes (E) (from three biologically independent replicates).

co-injected into the pronucleus and cytoplasm of 238 zygotes $\left(1^{\text {st }}\right.$ round $37,2^{\text {nd }}$ round 47 , and $3^{\text {rd }}$ round 154$)$ and resulted in a total of 35 pups. The final injection concentration in the mixture was $10 \mathrm{ng} / \mu \mathrm{l}$ Cas9n and $5 \mathrm{ng} / \mu \mathrm{l}$ of each sgRNA. After injection and incubation in $5.5 \% \mathrm{CO}_{2}$ at $37^{\circ} \mathrm{C}$ overnight for $24 \mathrm{~h}$, surviving 2-cell stage embryos were transferred to female NOD pseudopregnant recipients via oviduct transfer.

\section{Characterization of CRISPR/CAS9n genetic alterations}

Genomic DNA was extracted from tail snips of the 3521 day-old F0 mice using the DNeasy blood and tissue kit (Qiagen). The target region was PCR amplified by PuReTaq ReadyTo-Go PCR beads (GE Healthcare) followed by IndelCheck CRISPR/TALEN insertion or deletion detection system (GeneCopoeia). Successful genetic editing of the Zbtb32 gene was 
observed in 15 of the 35 pups. Genomic DNA from pups with evidence of deletion was further PCR amplified and subsequently cloned by TOPO T/A subcloning (Invitrogen, Carlsbad, CA) followed by DNA sequencing. Compound heterozygous null founders were bred with wildtype NOD animals to provide four potential alleles (named A, B, C, and D) for the creation of a NOD.Zbtb32 $2^{--}$colony. All four mutant alleles were sequenced to verify a successful deletion (Supplementary Table 1). As expected, the mutant alleles displayed a variety of deletion sizes due to differential DNA repair. Sibling crosses with matching mutant alleles were set up but, only mice carrying the mutant B allele were reliable breeders. Therefore, all NOD.Zbtb32 $2^{--}$ mice described in this paper are homozygous for the $\mathrm{B}$ allele.

\section{Genotyping and sequencing}

For routine genotyping and sequencing, we used the following PCR primers: forward 5'-AGCTG GCCTT TGGCT TAGTT-3' and reverse 5'-CAAAG GTGGA AGGGC TTATG-3'. Binding sites for these primers in relation to the CRISPR/Cas9 deletion are indicated in Figure 1A. PCR conditions followed a typical 3-temp program; $95^{\circ} \mathrm{C}$ for $5 \mathrm{~min},\left[95^{\circ} \mathrm{C} 30 \mathrm{~s}, 55^{\circ} \mathrm{C} 30 \mathrm{~s}, 72^{\circ} \mathrm{C} 45 \mathrm{~s}\right]$ repeat 34 times, and finally $72^{\circ} \mathrm{C}$ for $10 \mathrm{~min}$. The PCR results were run out on a $2 \%$ agarose gel. Single pass DNA sequencing services (ACGT, Inc., Germantown, MD) were carried out on genomic DNA using the reverse primer.

\section{Western blotting}

During dissections, mice were euthanized by $\mathrm{CO} 2$ asphyxiation and then the spleen was removed and placed in ice-cold PBS. Splenocytes were negatively enriched for $\mathrm{CD}^{+} \mathrm{T}$ cells using magnetic beads via the mouse $\mathrm{CD}^{+} \mathrm{T}$ Cell Isolation Kit (Miltenyi Biotech, Bergisch Gladbach, Germany) and then were incubated with Armenian Hamster anti-mouse CD3 (clone 145-2C11, Biolegend cat\#100301) and Syrian Hamster anti-mouse CD28 (clone 37.51, Biolegend cat\#102111) for either $14 \mathrm{~h}$ or $24 \mathrm{~h}$ at $37^{\circ} \mathrm{C}$ in T-cell Media (RPMI-1640+10\% FBS+L-glutamine + Penn/Strep). The cells were then pelleted and lysed used RIPA buffer supplemented with Protease Inhibitor Cocktail (Roche, Indianapolis, IN). A total of $35 \mu \mathrm{g}$ of protein was loaded into a NuPAGE 4-12\% Bis-Tris gel, transferred onto nitrocellulose, blocked in $5 \%$ milk for 1 hour at $25^{\circ} \mathrm{C}$, and blotted for Zbtb32 using rabbit anti-mouse sc-25358 (Santa Cruz Biotech, Santa Cruz CA) at a 1:500 dilution overnight at $4^{\circ} \mathrm{C}$. The membrane was then washed prior to the addition of goat-anti-rabbit HRP (Jackson Immunoresearch cat\#111035-003) at a dilution of 1:5,000 dilution at 1 hour at $25^{\circ} \mathrm{C}$. The membrane was then stripped, reblocked and reblotted for Lamin B using goat anti-mouse sc-6217 at a 1:5,000 dilution for 1 hour at $25^{\circ} \mathrm{C}$. The membrane was then washed prior to the addition of donkey anti-goat HRP (Jackson Immunoresearch cat\#705-035-003) at a dilution of 1:5,000 dilution for 45 minutes at $25^{\circ} \mathrm{C}$. All protein bands were imaged on a BioRad ChemiDoc CCD system and processed with the BioRad Image Lab 6.0 software.

\section{Ex vivo stimulations and cytokine staining}

Splenocytes and lymphocytes were stimulated with anti-mouse CD3 (145-2C11; BioLegend, San Diego, CA). A total of $5 \times 10^{5}$ cells were incubated for 18 hours at $37^{\circ} \mathrm{C}$ in T-cell media with either $0,10,100$, or $1000 \mathrm{ng}$ of anti-CD3 in a $300 \mu \mathrm{l}$ volume. For cytokine staining, cells were stimulated with PMA and Ionomycin in T-cell Media for 5 hours at $37^{\circ} \mathrm{C}$. Brefeldin A was added to all cells for the final 4 hours of stimulation. Cells were then fixed and stained for flow cytometry. FMO staining controls were performed using a mixture of both unstimulated and stimulated cells.

\section{Flow cytometry}

All cells were washed in Wash Buffer $[\mathrm{PBS}+2 \% \mathrm{FBS}]$ and then blocked with LEAF purified anti-CD16/32 (clone 93) on ice for 30 minutes prior to staining for flow cytometry. The Foxp3 (FJK-16s) antibodies were purchased from eBioscience (San Diego, CA). Foxp3 antibodies were diluted at 1:50 in Wash Buffer for cell staining, while all other antibodies were diluted at 1:100 in Wash Buffer. Staining was carried out for a minimum of 1 hour at $4^{\circ} \mathrm{C}$. Antibodies purchased from Biolegend (San Diego, CA) are listed alongside their clone and Antibody Registry numbers. We used antibodies raised against mouse B220 (RA3-6B2, RRID: AB_11203907), CD1d (CD1.1, RRID:AB_2715919), CD4 (GK1.5, RRID:AB_312690), CD5 (53-7.3, RRID:AB_312736), CD11b (M1/70, RRID:AB_312798), CD8 (53-6.7, RRID: AB_2561352), CD19 (6D5, RRID:AB_130884), CD23 (B3B4, RRID:AB_10060129), CD25 (PC61, RRID:AB_2562611), CD43 (S11, RRID:AB_2563698), CD44 (IM7, RRID:AB_2621762), CD62L (MEL-14, RRID:AB_10555750), CD69 (H1.2F3, RRID: AB_10683447), CD335 (29A1.4, RRID:AB_10827686), IFN $\gamma$ (XMG1.2, RRID:AB_469504). Cell viability was assessed by Fixable Live/Dead Aqua staining (Life Technologies, Grand Island, NY) according to the manufacturer's protocol. Cell proliferation was measured using the Cell Trace Violet Kit (Life Technologies, Grand Island, NY) according to the manufacturer's protocol. For cell fixation, permeabilization, and intracellular staining, we utilized the Intracellular Fixation \& Permeabilization Buffer Set from eBiosciences. All samples were run on a BD Biosciences LSR-II cytometer and later analyzed using FlowJo v9.4.1. For analysis, CD44 expression was measured by mean fluorescence intensity (MFI) rather than by the percentage of positive expression.

\section{Statistical analysis}

Statistical analysis for all experiments was carried out using GraphPad Prism v5. Where appropriate, statistical significance was calculated using either a Kaplan-Meier survival method (for disease incidence), or a two-way ANOVA tests for independent samples with post hoc Bonferroni comparisons for each possible pair of groups (used for all other data). Any significant differences $(P<0.05)$ between the two control strains are denoted with an asterisk. All dot plots show exact data points with a horizontal line denoting the average. All histograms show the average and standard deviation for the data.

\section{Results}

Using CRISPR techniques to generate knockout mutations directly in the NOD genetic background

The NOD mouse is an important model for examining spontaneous and chronic autoimmune disease, but it has been difficult to obtain genetically modified NOD mice due to the lack of 
a robust NOD ES cell line ${ }^{19}$. Directly targeting mutations into the NOD genetic background via CRISPR gene editing in NOD embryos is now possible ${ }^{20}$. Matching sgRNAs in exon 2 of Zbtb32 (Figure 1A and B) and CAS9n were injected into 2 cellstage embryos. Using the CAS9n with nickase activity ensures that an insertion or deletion can only occur if CAS9n binds to both sgRNAs, vastly reducing off-target events ${ }^{21}$. Four female mice carrying a suitable deletion were selected to be potential F0 founders (indicated in Figure 1C) and were crossed with wildtype NOD mice to produce heterozygous mice in the F1 generation. Two of these potential F0 founders were found to be germline compound heterozygous for the loss of Zbtb32, providing up to four potential alleles (listed in Supplementary Table 1 as alleles A, B, C, and D) for the creation of a NOD.Zbtb32 $2^{-1-}$ colony. Sibling crosses with matching mutant alleles were set up using the F1 generation. Because mice carrying the mutant $\mathrm{B}$ allele were the most reliable breeders, all NOD.Zbtb32 $2^{-/}$ mice described in this paper are homozygous for the $\mathrm{B}$ allele containing a $146 \mathrm{bp}$ frameshift deletion.

We designed PCR primers to serve for both routine genotyping purposes (demonstrated in Figure 1D) and as sequencing primers. Genomic sequencing on select NOD.Zbtb32 $2^{-/-}$mice from multiple generations verified that the deletion within the Zbtb32 gene was stable (Supplementary Figure 1). In wildtype NOD mice, Zbtb32 was not detectable at baseline in resting CD4+ lymphocytes, but could be detected by Western blot as early as 14 hours post anti-CD3/CD28 stimulation (Figure 1E). No Zbtb32 protein was observed in NOD.Zbtb32-- mice at either baseline or post-stimulation (Figure 1E).

\section{Dataset 1. Raw images for Figure 1 \\ http://dx.doi.org/10.5256/f1000research.13864.d197441 \\ The raw images for the genotyping gels and western blots seen in Figure 1.}

\section{Diabetes incidence in NOD.Zbtb32- mice}

To test the hypothesis that absence of Zbtb32 would increase diabetes pathogenesis in NOD mice, we monitored diabetes via blood glucose levels in NOD.Zbtb32 $2^{--}$mice and their control littermates for up to 35 weeks for both female (Figure 2A) and male mice (Figure 2B). NOD mice normally spontaneously develop hyperglycemia, between 12 and 30 weeks of age due to autoimmune destruction of the insulin secreting $\beta$-islet cells within the pancreas. The diabetes incidence rates showed no statistical differences between NOD.Zbtb32 $2^{--}$mice and their wildtype littermate controls when using a standard Kaplan-Meir survival test, but the male NOD.Zbtb32 $2^{-/}$trended toward a higher than expected total diabetes incidence (Figure 2C). Therefore, the trend in higher male disease incidence may indicate a mild

\section{A}

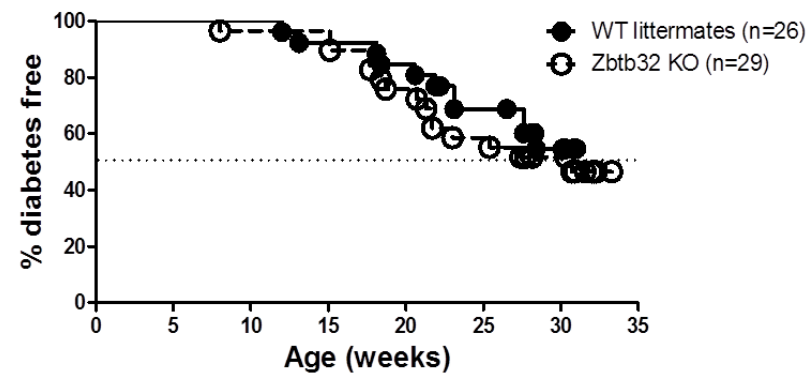

B
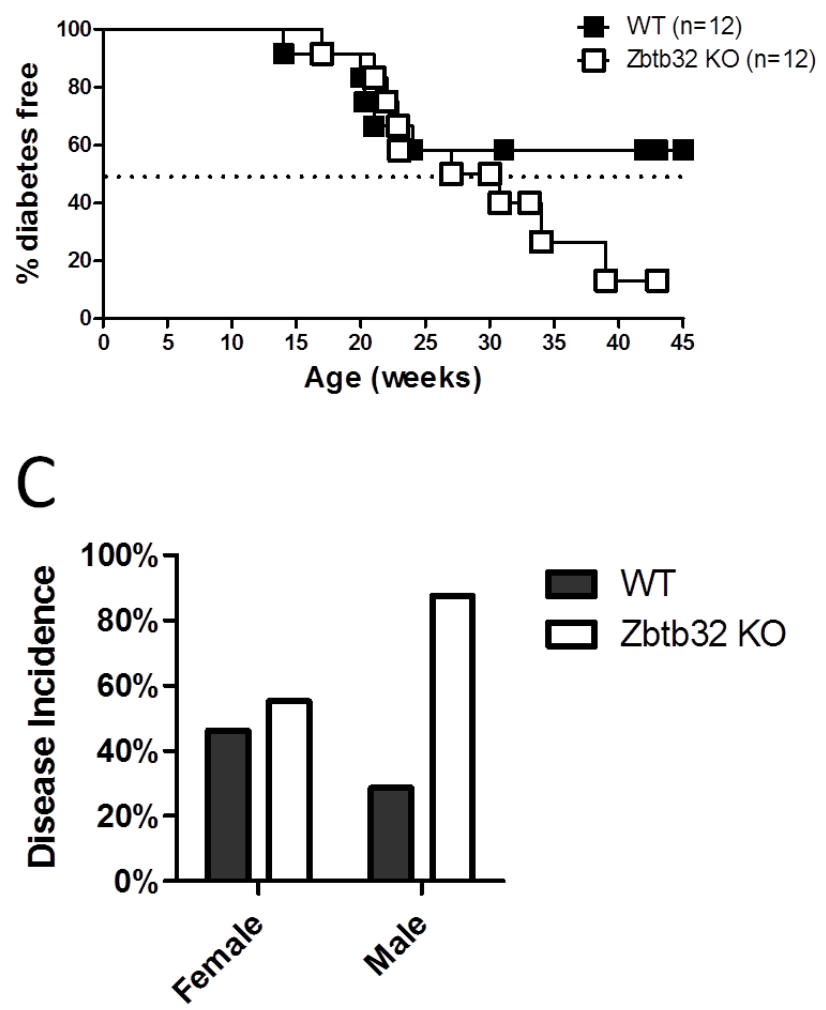

Figure 2. Diabetes incidence in NOD.Zbtb32- mice. The onset of Type 1 diabetes was monitored in our NOD.Zbtb32- colony by weekly blood glucose monitoring for both female $(\mathbf{A})$ and male (B) mice. Disease incidence rates were followed for littermate wildtype, and homozygous knockout mice. Disease incidence rates for males and females were plotted in (C). 
phenotype in NOD.Zbtb32-/ mice may impact disease onset over long timescales.

\section{Ex vivo T cell numbers and activation levels are not significantly altered in NOD.Zbtb32-/- mice}

Potential differences between wildtype and Zbtb32 $2^{-1}$ lymphocyte phenotype of both male and female mice at 8 weeks of age were tested using flow cytometry. Activation markers on Foxp $3^{+}$ regulatory $\mathrm{T}$ cells (Tregs), conventional $\mathrm{CD}^{+} \mathrm{T}$ cells (Tcons), and $\mathrm{CD}^{+} \mathrm{T}$ cells were measured without exogenous stimulation. As expected, higher activation was measured in the pancreaticdraining lymph nodes (pLNs) (Figure 3) compared to the spleen (Supplementary Figure 2), consistent with an autoimmune reaction to antigens acquired from pancreatic tissue. However, no statistically significant differences were observed between the NOD.Zbtb32 ${ }^{--}$mice and their control littermates for percent $\mathrm{CD}^{+} 5^{+}$(Figure 3A), CD69+ (Figure 3B), or CD44 MFI (Figure 3C) (and Supplementary Figure 2A $-\mathrm{C}$ ). T cells from the NOD. Zbtb32 ${ }^{-1-} \mathrm{pLN}$, but not the spleen were more variable than the wildtype for these phenotypes, and in some comparisons trend higher (e.g. elevated CD25 expression in female CTLs seen in Figure $3 \mathrm{~A}$ ), suggesting a mild activation phenotype.

In vitro stimulation of splenocytes is not significantly altered in NOD.Zbtb32-/- mice

In previous reports describing Zbtb32 gene deletion in other genetic backgrounds, reported phenotypes included T-cell hypersensitivity, increased proliferation, and increased cytokine production $^{10-12,14}$. We therefore carried out parallel experiments using splenocytes from the NOD.Zbtb32 $2^{-/}$mice. Splenocytes from both NOD.Zbtb32 $2^{--}$mice and NOD wildtype mice were stimulated with anti-CD3, and cell activation was assessed after $18 \mathrm{~h}$ by staining for surface CD69 (Figure 4A-C), CD44 (Figure 4D-F) and CD25 (Supplementary Figure 3A-C). $\mathrm{T}$ cell activation markers increased with anti-CD3 stimulation, but no significant differences between wildtype and Zbtb32 $2^{-/}$ lymphocytes were observed. Levels of cell proliferation after 48 hours of anti-CD3 stimulation, as measured by dilution of Cell Trace Violet dye, were also the same between NOD wildtype and Zbtb32--(Supplementary Figure 3D and E). We next measured cytokine production by stimulating splenocytes with PMA and Ionomycin, and detecting IFN $\gamma$ production in $\mathrm{CD}^{+}, \mathrm{CD}^{+}$, and $\mathrm{Nkp}_{4} 6^{+}$cells via intracellular cytokine staining. In all cases, the stimulation with PMA and Ionomycin produced the expected production of IFN $\gamma$, with higher expression in $\mathrm{CD}^{+}$and $\mathrm{Nkp}^{+} 6^{+}$cells. However, we did not find statistically significant differences between NOD.Zbtb32-splenocytes and their matching controls (Figure 4G-I). Therefore, unlike other Zbtb32- strains, ex vivo $\mathrm{T}$ cell responses from NOD.Zbtb32 $2^{--}$mice were not significantly altered.

No significant changes in peritoneal cavity $B$ cells in NOD.Zbtb32-/- mice

Because the $\mathrm{T}$ cell and diabetes phenotypes did not match the expected result based on overexpression of Zbtb32 in $\mathrm{T}$ cells ${ }^{6}$,
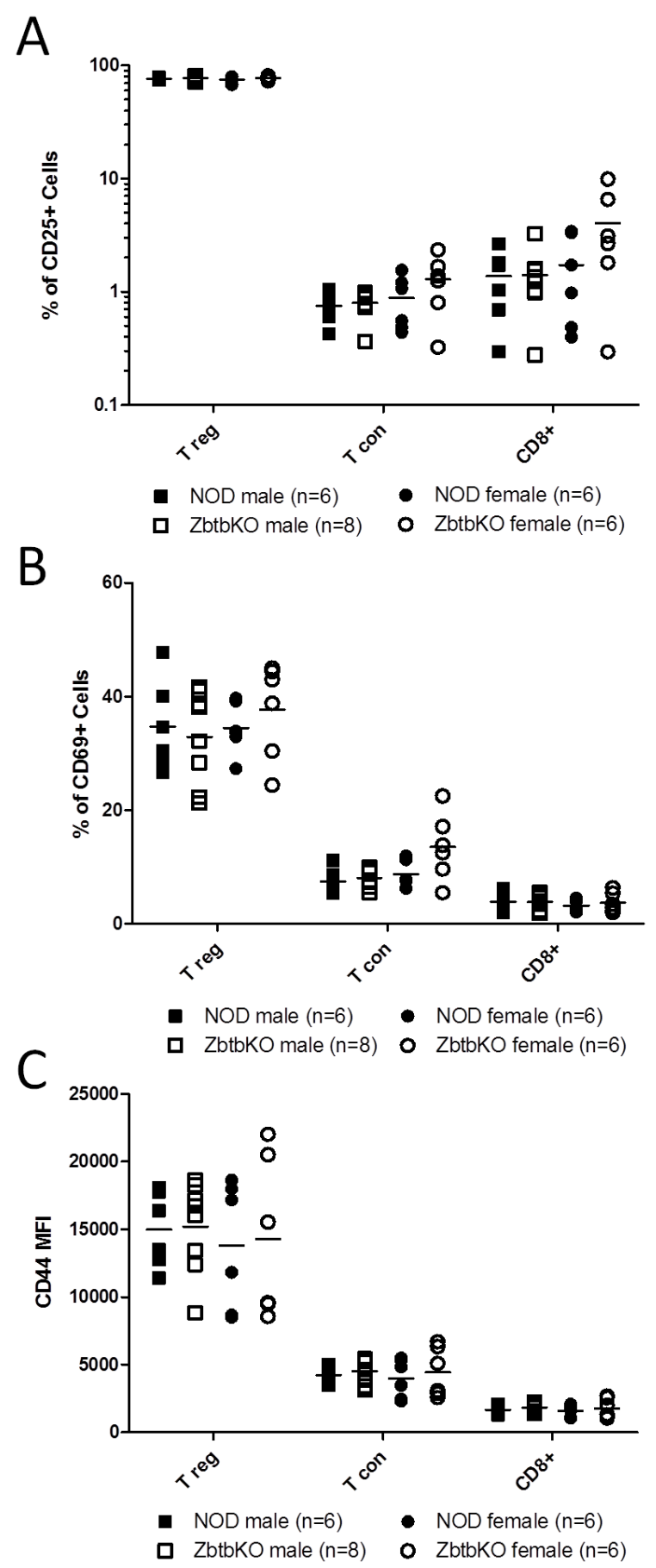

Figure 3. Activation markers on lymphocytes from pancreatic draining lymph node of Zbtb32-- mice. Lymphocytes from the pancreatic draining lymph node of male and female NOD and NOD. Zbtb32- mice were stained for activation markers. Flow cytometry was used to determine cell surface expression of CD25 (A) CD69 (B) and CD44 (C) on CD4+ Foxp3+ (Tregs), CD4+ Foxp3- (Tcon) and $\mathrm{CD}^{+} \mathrm{T}$ cells. The data were combined from two independent repeats of this experiment. 

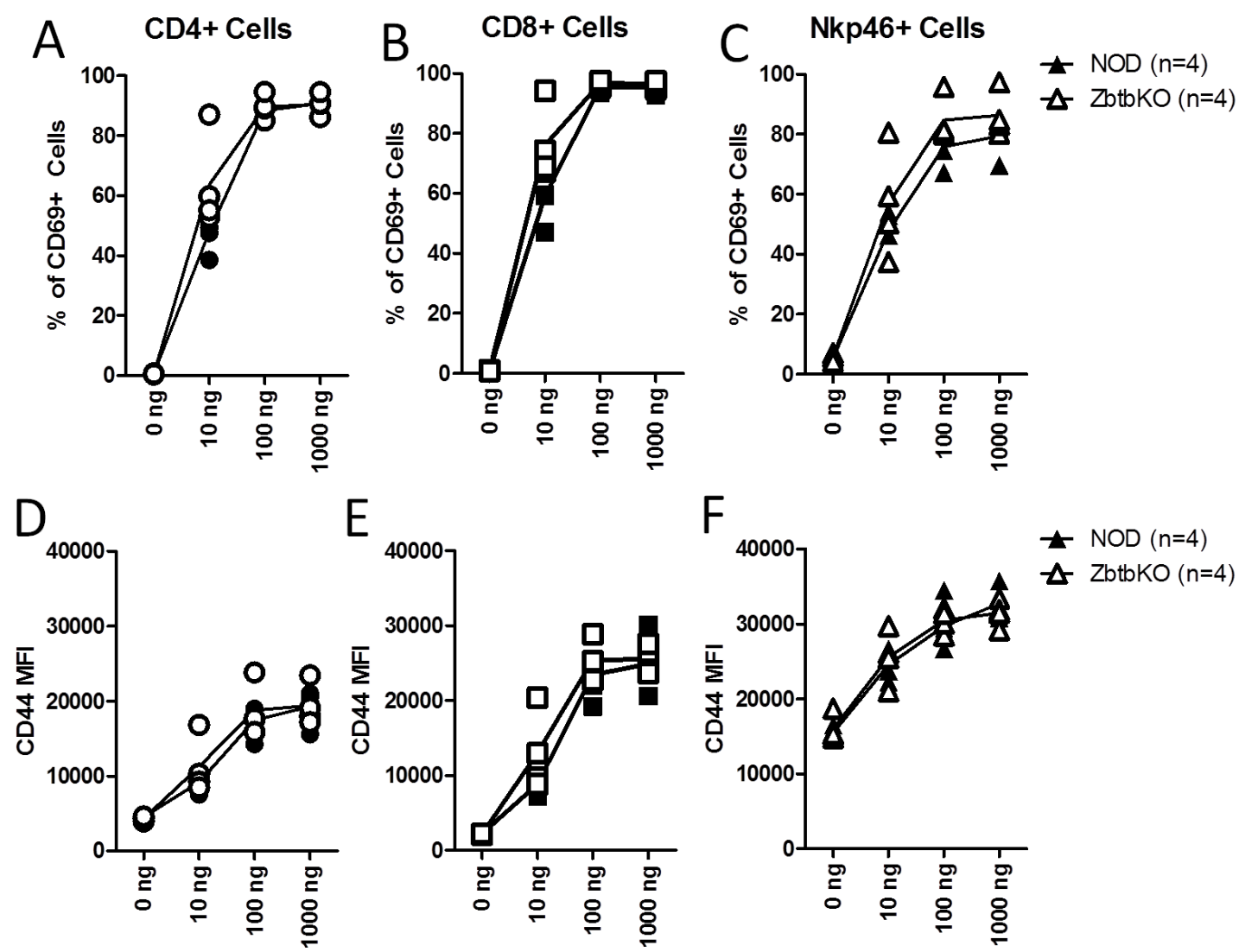

$\mathrm{E}$
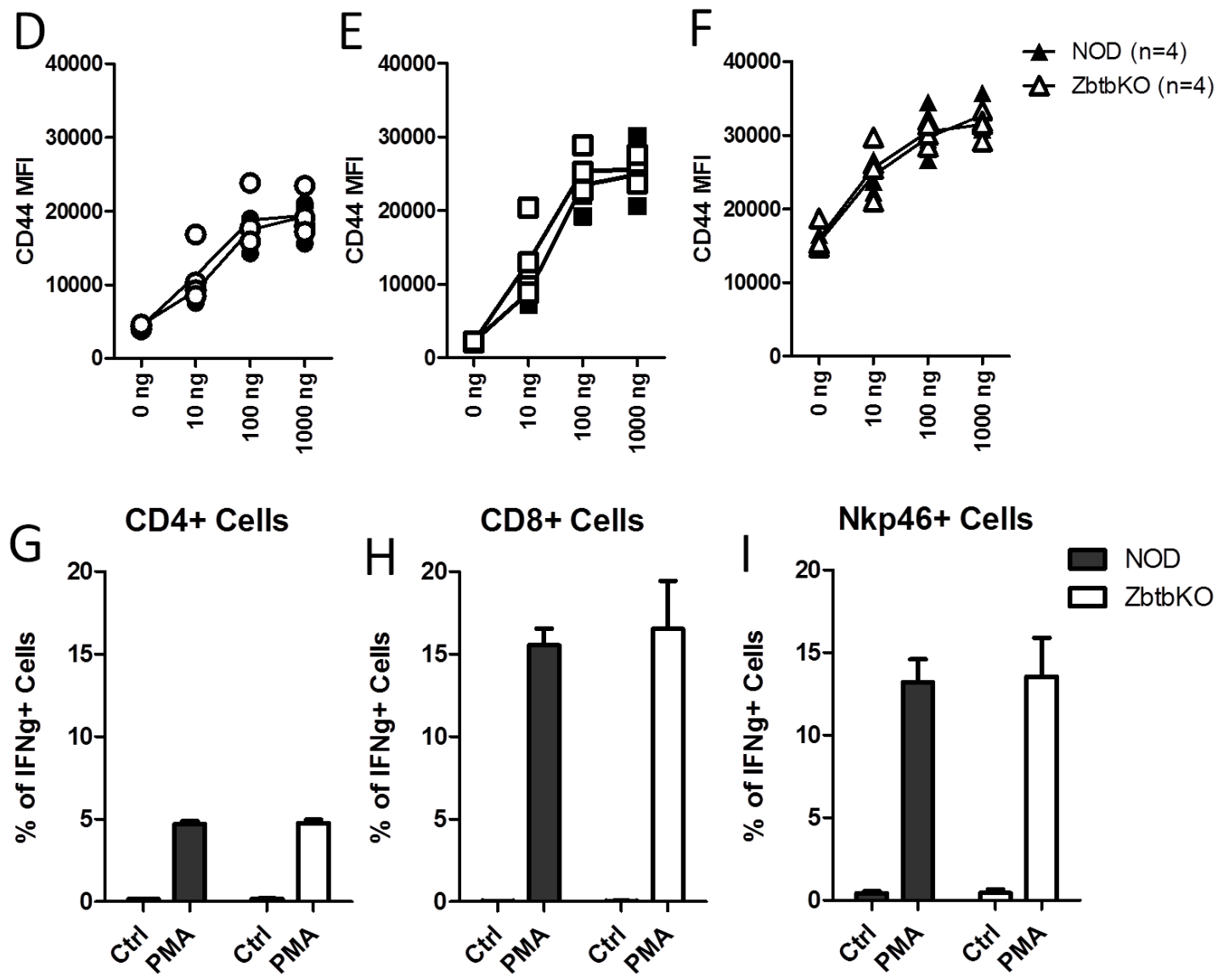

Figure 4. Activation markers and cytokine production in Zbtb32-- splenocytes after ex vivo stimulation. Freshly isolated splenocytes from female NOD.Zbtb32-- mice and control littermates were stimulated with the indicated dosages of anti-CD3 for $18 \mathrm{~h}$. Surface expression of CD69 (A-C) and CD44 (D-F) was measured on $\mathrm{CD}^{+}, \mathrm{CD}^{+}$, and NKp46 splenocytes. For IFN $\gamma$ staining, splenocytes from female NOD.Zbtb32- mice and their control littermates were stimulated with PMA and lonomycin for 4 hours (G-I). The percentage of cells positive for IFN $\gamma$ in $\mathrm{CD}^{+}(\mathbf{G}), \mathrm{CD}^{+}(\mathbf{H})$, and NKp46 ${ }^{+}$cells $(\mathbf{I})$ is shown. The data were combined from two independent repeats of this experiment.

potential effects of Zbtb32 deletion on other cell types was considered. B1 cells, which primarily reside in the peritoneal cavity, display a constitutively high expression of Zbtb32 22,23 . A related transcription factor, Zbtb20, was recently implicated as a regulator of terminal differentiation in germinal center B cells ${ }^{24}$. The authors proposed that either Zbtb20 or Zbtb32 may play a critical role in either B1 cell proliferation or differentiation. $\mathrm{B} 1$ cells can be further divided into $\mathrm{B} 1 \mathrm{a}$ and $\mathrm{B} 1 \mathrm{~b}$ cells based on their surface expression of $\mathrm{CD}^{25}$. In NOD mice, B1 cells can be identified as $\mathrm{CD} 19^{+} \mathrm{B} 220^{+} \mathrm{CD} 11 \mathrm{~b}^{+} \mathrm{CD} 43^{+}$, with $\mathrm{CD}^{+}$and $\mathrm{CD}^{-}$subpopulations being labeled as $\mathrm{B} 1 \mathrm{a}$ and $\mathrm{B} 1 \mathrm{~b}$, respectively (Figure 5). Since prior reports had indicated that Zbtb32 can 


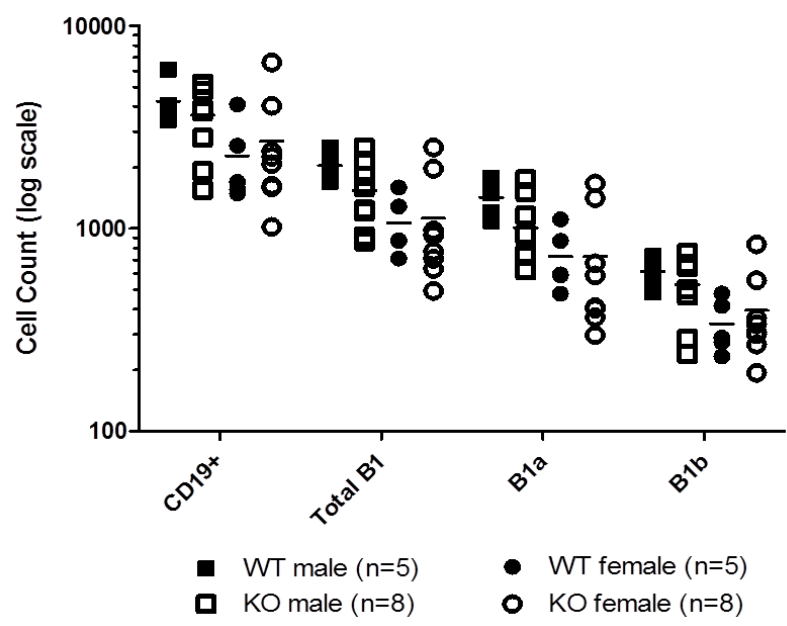

Figure 5. B cell populations within the peritoneal cavity. The number of $\mathrm{B}$ cells in the peritoneal cavity of 4 week-old mice were measured, including all CD19+ cells, all B1 cells, and the subpopulations of B1a and B1b cells. The data were combined from two independent experiments.

regulate early $\mathrm{B}$ cell proliferation ${ }^{26}$, B1 populations in the peritoneal cavity of NOD.Zbtb32 $2^{-/}$mice and their wildtype controls were examined at 4 weeks of age (Figure 5). NOD.Zbtb32 $2^{-/}$mice trended toward fewer total B cells in their peritoneal cavity. But no statistically significant differences were observed in the proportion of $\mathrm{B} 1$ cells among all $\mathrm{CD} 19^{+}$cells between wildtype NOD and NOD.Zbtb32- mice (analysis not shown). Therefore, the mild diabetes phenotype and the absence of the expected $\mathrm{T}$ cell activation phenotype are unlikely to be due to effects on B1 cells.

Dataset 2. Raw data for blood glucose from Figure 2

http://dx.doi.org/10.5256/f1000research.13864.d197442

The raw data values and the GraphPad Prism fole for blood glucose measurements.

Dataset 3. Raw flow cytometry data from 8 week-old mice http://dx.doi.org/10.5256/f1000research.13864.d197443

Raw flow cytometry sample data and the FlowJo analysis file for resting splenocytes and lymphocytes from 8 week old mice.

Dataset 4. Raw flow cytometry data from ex vivo stimulated splenocytes

http://dx.doi.org/10.5256/f1000research.13864.d197444

Raw flow cytometry sample data and the FlowJo analysis file for ex vivo stimulated splenocytes, including cell proliferation and cytokine production.

\section{Dataset 5.}

http://dx.doi.org/10.5256/f1000research.13864.d197445

Diabetes incidence in NOD.Zbtb32-/- mice.

\section{Dataset 6.}

http://dx.doi.org/10.5256/f1000research.13864.d197446

Alignment.

\section{Discussion}

We previously focused on Zbtb32 as a potential regulator of $\mathrm{T}$ cell tolerance in the NOD mouse model, and found that this transcription regulator was preferentially induced in autoreactive $\mathrm{CD}^{+} \mathrm{T}$ cells after interacting with tolerogenic DCIR2 ${ }^{+} \mathrm{DCs}$, and that overexpression in $\mathrm{T}$ cells inhibited both diabetes and effector $\mathrm{T}$ cell expansion ${ }^{6}$. The available literature corroborated these findings but did not provide insight into how Zbtb32 might control $\mathrm{T}$ cell development and tolerance in a spontaneous autoimmune disease such as $\mathrm{T}^{1} \mathrm{D}^{9-11,27}$. We initially hypothesized that the Zbtb32 $2^{--}$mutation in NOD mice would result in hyperactive $\mathrm{T}$ cells and increased diabetes. Instead, no significant changes in disease incidence in the NOD.Zbtb $32^{-/}$mice were observed, and the increased $\mathrm{T}$ cell activation and differentiation observed in mutants from other genetic backgrounds were absent. No significant shifts in the number or percentage of the major lymphocyte populations were observed. Furthermore, we observed that the loss of Zbtb32 had no impact on intraperitoneal B1 cells, despite the fact that it is constitutively expressed in those cells in wildtype animals. In most of these readouts, a trend towards the expected phenotype was observed, suggesting a very mild phenotype, with only the long-term male disease incidence rates provided any evidence that the loss of Zbtb32 affected T1D disease pathogenesis. Although NOD females normally have higher incidence than males, this phenotype can vary greatly, and $50 \%$ incidence is within range of what we have observed for our colony (20-50\% in males and $40-90 \%$ in females).

Prior investigations of Zbtb32 knockout mice in other genetic backgrounds consistently showed an activated $\mathrm{T}$ cell phenotype that included hypersensitivity, increased cytokine production, and increased proliferation ${ }^{10-14}$. Furthermore, our results showed that overexpression of Zbtb32 delayed diabetes onset, limited T-cell proliferation, and decreased IFN $\gamma$ production from autoreactive $\mathrm{T}$ cells in an adoptive transfer model of T1D ${ }^{6}$. There are several possible reasons that may account for the observed lack of expected phenotype. One potential explanation for our unexpected results is that the CRISPR/Cas9 mediated deletion produced either an off-target effect or otherwise caused genetic instability at the deletion site. The use of CRISPR techniques in 
the NOD genetic background is a new approach that has, to our knowledge, only been described in two previous publications to date ${ }^{19,28}$. The CRIPSR/Cas9 mediated deletion was significantly smaller than other previously engineered Zbtb32 deletions (Compare Figure 1B to Supplementary Figure 4), but still disrupted the reading frame of the Zbtb32 gene. Our western blots (Figure 1E) demonstrated that the protein had been eliminated, and the use of CAS9n minimized other potential mutations. Nevertheless, we re-examined our colony for any evidence of genetic instability or off-target effects by re-sequencing archived genomic DNA from founder mice and five subsequent generations of sibling crosses and found that the mutations remained stable (Supplementary Figure 1) in every sequenced member of our NOD.Zbtb32 $2^{--}$colony. To identify potential off-target effects, we compared sequence homologies among all the transcription factors in the Zbtb family as well as sequence homologies for just the guide RNA strands used by the Cas9n enzyme. Both homology analyses indicated that only Zbtb16 was a potential target for unintended genetic editing. However, sequencing the Zbtb16 gene in multiple generations of the NOD.Zbtb32 $2^{-/}$mouse colony revealed no off-target mutations of Zbtb16 (data not shown). These results therefore argue against the idea that our overall lack of phenotype can be explained by erroneous CRISPR/Cas9 activity.

Genetic backgrounds can have a dramatic effect as genetic alterations combine to either mask or exacerbate disease phenotypes $^{29}$. Interestingly, the role of Zbtb32 in immune tolerance was examined in the $\mathrm{BALB} / \mathrm{c}$ strain by using the Experimental Autoimmune Encephalitis (EAE) model. The loss of Zbtb32 in BALB/c mice had no significant impact on the EAE clinical score or timing of onset of paralysis suggest that the loss of Zbtb32, despite the observed activated $\mathrm{T}$ cell phenotype, was not sufficient to precipitate severe autoimmunity ${ }^{11}$. A rapid and induced autoimmune model like EAE differs significantly from a spontaneous, chronic disease model like NOD, but the parallel results between our findings and the findings in Kang et $a l .{ }^{11}$ suggest that, in some contexts, other genes may be able to compensate for the loss of Zbtb32. Further support for this explanation comes from an examination of regulatory transcription factors in $\mathrm{T}_{\mathrm{H}}$ 17-mediated autoimmune pathology ${ }^{30}$. The authors found that although Zbtb32 gene expression was highly correlated with a protective phenotype, the loss of the Zbtb32 gene in the $129 / \mathrm{Sv}$ background did not produce the expected hypersensitive $\mathrm{T}_{\mathrm{H}} 17$ response and instead observed a diminished $\mathrm{T}_{\mathrm{H}} 17$ response after repeated stimulations. Based on their gene expression data, Gaublomme et al. hypothesized that while Zbtb32 normally suppresses pro-inflammatory responses, other unidentified transcription factors continued to upregulate pro-regulatory genes and therefore mask the expected phenotype in $\mathrm{T}_{\mathrm{H}} 17$ responses $^{30}$. The NOD.Zbtb32- mice differed from past knockout strains in terms of the $\mathrm{T}$ cell response. Examinations of lymphocytes from the pLNs (Figure 3) and the spleen (Supplementary Figure 2) revealed only mild differences between wildtype and knockout littermates in NOD mice. Considering that the target pancreatic antigens are trafficked into the pLNs and by 8 weeks of age NOD mice display chronic autoimmunity and lymphocytic infiltration in the pancreatic islets ${ }^{31,32}$, we had expected to find increased levels of lymphocyte activation in the pLNs. The major phenotype observed in other $\mathrm{Zbtb}^{-{ }^{--}}$strains was a hyperreactivity to in vitro $\mathrm{T}$ cell stimulation, manifest in higher proliferation and cytokine production ${ }^{10,11,14,26}$. However, $\mathrm{T}$ cells from NOD.Zbtb32-- mice showed no increase in proliferation or IFN $\gamma$ production in response to in vitro stimulation.

It is possible that the lack of phenotype in the NOD genetic background, but not other backgrounds, was due to compensation from homologous proteins. The loss of Zbtb32 from birth could activate compensatory mechanisms in NOD mice that obscure any overt abnormalities in adult mice. It is even possible that a compensatory mechanism was selected for in the course of breeding NOD.Zbtb32 $2^{--}$mice. Our incidence data includes one mutant mouse from our first generation of the colony that developed hyperglycemia at an abnormally early age (8 weeks), and three out of the four mutated alleles proved to be poor breeders. Zbtb32 is constitutively expressed in the testis ${ }^{33}$, but its role in fertility is not clear $^{34}$. These unexpected results could potentially be explained by compensatory mechanisms that were either already present within the NOD genetic background, or were selected for during the generation of this NOD.Zbtb32 $2^{-/}$mouse colony. Therefore, an alternative approach targeting expression in adults could yield a different result.

Taken together, our results show that the systemic loss of Zbtb32 in NOD mice does not lead to a hypersensitive T cell phenotype and increased diabetes pathogenesis. Although the NOD.Zbtb32-male mice displayed some increase in diabetes incidence compared to littermate controls, these trends did not reach statistical significance. Therefore, we conclude that NOD mice with the loss of Zbtb32 have a mild phenotype that may be a result of compensation by a currently unknown mechanism. In a broader context, these data do not support a major role for Zbtb32 as a target for treatment of autoimmune diabetes.

\section{Data availability}

Dataset 1: Raw images for Figure 1 The raw images for the genotyping gels and western blots seen in Figure 1. 10.5256/ f1000research.13864.d197441 ${ }^{35}$

Dataset 2: Raw data for blood glucose from Figure 2 The raw data values and the GraphPad Prism fole for blood glucose measurements. 10.5256/f1000research.13864.d197442 ${ }^{36}$

Dataset 3: Raw flow cytometry data from 8 week-old mice: Raw flow cytometry sample data and the FlowJo analysis file for resting splenocytes and lymphocytes from 8 week old mice. 10.5256/ f1000research.13864.d19744337 
Dataset 4: Raw flow cytometry data from ex vivo stimulated splenocytes: Raw flow cytometry sample data and the FlowJo analysis file for ex vivo stimulated splenocytes, including cell proliferation and cytokine production 10.5256/f1000research.13864. d197444 ${ }^{38}$

Dataset 5: Diabetes incidence in NOD.Zbtb32 $2^{-/}$mice $10.5256 /$ f1000research.13864.d197445 ${ }^{39}$

Dataset 6: Alignment 10.5256/f1000research.13864.d19744640

Competing interests

Kristin Tarbell is currently an employee of Amgen; all work described here was performed at NIDDK and has received no financial support from Amgen.
Grant information

This work was supported by the Intramural Research Program of the National Institute of Diabetes and Digestive and Kidney Diseases, Project \# 1ZIADK075065-06.

The funders had no role in study design, data collection and analysis, decision to publish, or preparation of the manuscript.

\section{Acknowledgements}

We would like to thank Mrs. Alice Franks (DEOB, NIDDK) for mouse colony management, the NHLBI/NIDDK flow core for assistance with flow cytometry, System Biosciences for help designing the sgRNA sequences, and Huiyan Lu for assistance with carrying out genetic manipulation and transference of embryos.

\section{Supplementary material}

Supplementary Table 1. Alignment of NOD.Zbtb32 mutant alleles. The four mutant alleles of Zbtb32 that were produced by CRISPR/ Cas9 were then sequenced and aligned. Allele B was chosen to serve as the only mutation in the colony.

Click here to access the data.

Supplemental Figure 1. The CRISPR/Cas9 deletion remained stable in the NOD.Zbtb32 colony. We archived breeder genealogies and genomic DNA from all mice in the NOD.Zbtb32 mouse colony. A genealogy of breeding cages carrying the B allele of the mutated Zbtb32 gene is depicted in (A). A total of 16 archived DNA samples were sequenced and then aligned in order to verify that the mutation remained stable in the colony $(\mathbf{B})$. These archived samples included 1 founder of the B line, 13 homozygous knockout descendants, and 2 homozygous wildtype offspring.

Click here to access the data.

Supplemental Figure 2. Activation markers from resting splenocytes in NOD.Zbtb32-/ mice. We examined populations of Treg, Tcon, and $\mathrm{CD}^{+} \mathrm{T}$ cells in freshly dissected spleens from both male and female mice and their littermate controls. Flow cytometry was used to determine the ratio of $\mathrm{CD}_{25} 5^{+}(\mathbf{A}) \mathrm{CD}^{+} 9^{+}(\mathbf{B})$ and cell surface expression of CD44 (C) on the indicated splenocytes.

Click here to access the data.

Supplemental Figure 3. Activation markers on ex vivo-stimulated lymphocytes from pancreatic draining lymph nodes. After isolating lymphocytes from the pancreatic draining lymph nodes of NOD.Zbtb32-- mice and stimulating them with anti-CD3 as indicated, we stained for activation markers in both male and female mice as well as their matching controls. Flow cytometry was used to determine the ratio expressing $\mathrm{CD} 25(\mathbf{A}-\mathbf{C})$ for $\mathrm{CD}^{+}, \mathrm{CD}^{+}$, and $\mathrm{Nkp}^{+} 6^{+}$splenocytes. Additionally, we measured cell proliferation in splenocytes after $48 \mathrm{~h}$ in response to $1000 \mathrm{ng}$ of anti-CD3 $(\mathbf{D} \& \mathbf{E})$.

Click here to access the data.

Supplemental Figure 4. Other zbtb32 KO maps. For comparison purposes, the mutant mRNA sequences that arise from each of the previous 3 mutant strains are depicted here. The mature mRNAs contain no introns, and non-coding portions are shown as thinner than the coding portions. Each of the previous three mutants was produced by deleting large portions of the Zbtb32 gene and replacing the sequence with selection and/or reporter genes.

Click here to access the data. 
1. Miller KM, Foster NC, Beck RW, et al.: Current state of type 1 diabetes treatment in the U.S.: updated data from the T1D Exchange clinic registry. Diabetes Care. 2015; 38(6): 971-978

PubMed Abstract | Publisher Full Text

2. Audiger C, Rahman MJ, Yun TJ, et al:: The importance of dendritic cells in maintaining immune tolerance. J Immunol. 2017; 198(6): 2223-2231. PubMed Abstract | Publisher Full Text | Free Full Text

3. Hotta-Iwamura C, Tarbell KV: Type 1 diabetes genetic susceptibility and dendritic cell function: potential targets for treatment. J Leukoc Biol. 2016 100(1): 65-80.

PubMed Abstract | Publisher Full Text | Free Full Text

4. Yamazaki S, Inaba K, Tarbell KV, et al.: Dendritic cells expand antigen-specific $\mathrm{Foxp}^{+} \mathrm{CD}^{+} \mathrm{CD}^{+} \mathrm{CD}^{+}$regulatory $\mathrm{T}$ cells including suppressors of alloreactivity. Immunol Rev. 2006; 212: 314-329.

PubMed Abstract | Publisher Full Text

5. Price JD, Beauchamp NM, Rahir G, et al.: CD8 ${ }^{+}$dendritic cell-mediated tolerance of autoreactive $\mathrm{CD4}^{+} \mathrm{T}$ cells is deficient in NOD mice and can be corrected by blocking CD40L. J Leukoc Biol. 2014; 95(2): 325-336.

PubMed Abstract | Publisher Full Text | Free Full Text

6. Price JD, Hotta-Iwamura C, Zhao Y, et al.: DCIR2+ ${ }^{+}$CDC2 DCs and Zbtb32 Restore CD4 ${ }^{+}$T-Cell Tolerance and Inhibit Diabetes. Diabetes. 2015; 64(10): 3521-3531.

PubMed Abstract | Publisher Full Text | Free Full Text

7. Hoatlin ME, Zhi $Y$, Ball $\mathrm{H}$, et al: A novel BTB/POZ transcriptional repressor protein interacts with the Fanconi anemia group C protein and PLZF. Blood. 1999; 94(11): 3737-3747.

PubMed Abstract

8. Tang CJ, Chuang CK, Hu HM, et al:: The zinc finger domain of Tzfp binds to the tbs motif located at the upstream flanking region of the Aie1 (aurora-C) kinase gene. J Biol Chem. 2001; 276(22): 19631-19639.

PubMed Abstract | Publisher Full Text

9. Miaw SC, Choi A, Yu E, et al.: ROG, repressor of GATA, regulates the expression of cytokine genes. Immunity. 2000; 12(3): 323-333. PubMed Abstract | Publisher Full Text

10. Piazza F, Costoya JA, Merghoub T, et al.: Disruption of PLZP in mice leads to increased T-lymphocyte proliferation, cytokine production, and altered hematopoietic stem cell homeostasis. Mol Cell Biol. 2004; 24(23): 10456-10469. PubMed Abstract | Publisher Full Text | Free Full Text

11. Kang BY, Miaw SC, Ho IC: ROG negatively regulates T-cell activation but is dispensable for Th-cell differentiation. Mol Cell Biol. 2005; 25(2): 554-562. PubMed Abstract | Publisher Full Text | Free Full Text

12. Hirahara K, Yamashita M, Iwamura C, et al.: Repressor of GATA regulates TH2driven allergic airway inflammation and airway hyperresponsiveness. J Allergy Clin Immunol. 2008; 122(3): 512-20.e11.

PubMed Abstract | Publisher Full Text

13. Hirasaki Y, Iwamura C, Yamashita M, et al.: Repressor of GATA negatively regulates murine contact hypersensitivity through the inhibition of type-2 allergic responses. Clin Immunol. 2011; 139(3): 267-276.

PubMed Abstract | Publisher Full Text

14. Beaulieu AM, Zawislak CL, Nakayama T, et al:: The transcription factor Zbtb32 controls the proliferative burst of virus-specific natural killer cells responding to infection. Nat Immunol. 2014; 15(6): 546-553. PubMed Abstract | Publisher Full Text | Free Full Text

15. Jash A, Wang Y, Weisel FJ, et al:: ZBTB32 Restricts the Duration of Memory B Cell Recall Responses. J Immunol. 2016; 197(4): 1159-1168.

PubMed Abstract | Publisher Full Text | Free Full Text

16. Markel P, Shu P, Ebeling C, et al.: Theoretical and empirical issues for marker-assisted breeding of congenic mouse strains. Nat Genet. 1997; 17(3) 280-284.

PubMed Abstract | Publisher Full Text

17. Ohta $\mathrm{H}$, Ohinata $\mathrm{Y}$, Ikawa $\mathrm{M}$, et al:: Male germline and embryonic stem cell lines from NOD mice: efficient derivation of GS cells from a nonpermissive strain for ES cell derivation. Biol Reprod. 2009; 81(6): 1147-1153. PubMed Abstract | Publisher Full Text

18. Ridgway WM: A new tool for dissecting genetic control of type 1 diabetes. Diabetes. 2014; 63(1): 56-58.

PubMed Abstract | Publisher Full Text

19. Lin X, Pelletier S, Gingras S, et al:: CRISPR-Cas9-Mediated Modification of the NOD Mouse Genome With Ptpn22 ${ }^{\text {R619W }}$ Mutation Increases Autoimmune Diabetes. Diabetes. 2016; 65(8): 2134-2138.

PubMed Abstract | Publisher Full Text | Free Full Text

20. Fellmann C, Gowen BG, Lin PC, et al:: Cornerstones of CRISPR-Cas in drug discovery and therapy. Nat Rev Drug Discov. 2017; 16(2): 89-100 PubMed Abstract | Publisher Full Text | Free Full Text

21. Mali $\mathrm{P}$, Aach J, Stranges PB, et al.: CAS9 transcriptional activators for target specificity screening and paired nickases for cooperative genome engineering. Nat Biotechnol. 2013; 31(9): 833-838.

PubMed Abstract | Publisher Full Text | Free Full Text

22. Heng TS, Painter MW, Immunological Genome Project Consortium: The Immunological Genome Project: networks of gene expression in immune cells. Nat Immunol. 2008; 9(10): 1091-1094.

PubMed Abstract | Publisher Full Tex

23. Mabbott NA, Gray D: Identification of co-expressed gene signatures in mouse B1, marginal zone and B2 B-cell populations. Immunology. 2014; 141(1): 79-95. PubMed Abstract | Publisher Full Text | Free Full Text

24. Chevrier S, Emslie D, Shi W, et al:: The BTB-ZF transcription factor Zbtb20 is driven by Irf4 to promote plasma cell differentiation and longevity. J Exp Med. 2014; 211(5): 827-840.

PubMed Abstract | Publisher Full Text | Free Full Text

25. Hardy RR: B-1 B cell development. J Immunol. 2006; 177(5): 2749-2754 PubMed Abstract | Publisher Full Text

26. Yoon HS, Scharer CD, Majumder $P$, et al.: ZBTB32 is an early repressor of the CIITA and MHC class II gene expression during B cell differentiation to plasma cells. J Immunol. 2012; 189(5): 2393-2403.

PubMed Abstract | Publisher Full Text | Free Full Text

27. Miaw SC, Kang BY, White IA, et al:: A repressor of GATA-mediated negative feedback mechanism of T cell activation. J Immunol. 2004; 172(1): 170-177. PubMed Abstract | Publisher Full Text

28. Ratiu JJ, Racine JJ, Hasham MG, et al: Genetic and Small Molecule Disruption of the AID/RAD51 Axis Similarly Protects Nonobese Diabetic Mice from Type 1 Diabetes through Expansion of Regulatory B Lymphocytes. J Immunol. 2017; 198(11): 4255-4267.

PubMed Abstract | Publisher Full Text | Free Full Text

29. Coley WD, Bogdanik L, Vila MC, et al.: Effect of genetic background on the dystrophic phenotype in mdx mice. Hum Mol Genet. 2016; 25(1): 130-145. PubMed Abstract | Publisher Full Text | Free Full Text

30. Gaublomme JT, Yosef N, Lee Y, et al:: Single-Cell Genomics Unveils Critical Regulators of Th17 Cell Pathogenicity. Cell. 2015; 163(6): 1400-1412. PubMed Abstract | Publisher Full Text | Free Full Text

31. Höglund $\mathrm{P}$, Mintern $\mathrm{J}$, Waltzinger $\mathrm{C}$, et al:: Initiation of autoimmune diabetes by developmentally regulated presentation of islet cell antigens in the pancreatic lymph nodes. J Exp Med. 1999; 189(2): 331-339. PubMed Abstract | Publisher Full Text | Free Full Text

32. Miyazaki A, Hanafusa T, Yamada K, et al:: Predominance of T lymphocytes in pancreatic islets and spleen of pre-diabetic non-obese diabetic (NOD) mice: longitudinal study. Clin Exp Immunol. 1985; 60(3): 622-630. PubMed Abstract | Free Full Text

33. Lin W, Lai CH, Tang CJ, et al:: Identification and gene structure of a novel human PLZF-related transcription factor gene, TZFP. Biochem Biophys Res Commun. 1999; 264(3): 789-795 PubMed Abstract | Publisher Full Text

34. Jiang X, Zhang H, Yin S, et al:: Specific deficiency of PIzf paralog, Zbtb20, in Sertoli cells does not affect spermatogenesis and fertility in mice. Sci Rep. 2014; 4(1): 7062

PubMed Abstract | Publisher Full Text | Free Full Text

35. Tarbell K, Coley WD, Zhao Y, et al:: Dataset 1 in: Loss of Zbtb32 in NOD mice does not significantly alter T cell responses. F1000Research. 2018. Data Source

36. Tarbell K, Coley WD, Zhao Y, et al:: Dataset 2 in: Loss of Zbtb32 in NOD mice does not significantly alter T cell responses. F1000Research. 2018. Data Source

37. Tarbell K, Coley WD, Zhao Y, et al:: Dataset $\mathbf{3}$ in: Loss of Zbtb32 in NOD mice does not significantly alter T cell responses. F1000Research. 2018. Data Source

38. Tarbell K, Coley WD, Zhao Y, et al:: Dataset 4 in: Loss of Zbtb32 in NOD mice does not significantly alter T cell responses. F1000Research. 2018. Data Source

39. Tarbell K, Coley WD, Zhao Y, et al:: Dataset $\mathbf{5}$ in: Loss of Zbtb32 in NOD mice does not significantly alter T cell responses. F1000Research. 2018. Data Source

40. Tarbell K, Coley WD, Zhao Y, et al:: Dataset 6 in: Loss of Zbtb32 in NOD mice does not significantly alter T cell responses. F1000Research. 2018. Data Source 


\section{Open Peer Review}

\section{Current Peer Review Status:}

\section{Version 1}

Reviewer Report 19 April 2018

https://doi.org/10.5256/f1000research.15070.r32633

(C) 2018 Gerling I. This is an open access peer review report distributed under the terms of the Creative Commons Attribution License, which permits unrestricted use, distribution, and reproduction in any medium, provided the original work is properly cited.

\section{Ivan C. Gerling}

Department of Medicine, University of Tennessee Health Science Center, Memphis, TN, 38104, USA

This is an interesting "negative results" report. The authors had previously reported data in support of the hypothesis that systemic loss of the expression of the gene Zbtb32 would increase T-cell activation and increase diabetic pathogenesis. The expected hypersensitivity of leukocytes was not observed. A minor but non-significant increase in diabetes incidence was observed in males, but only at later than 30 weeks of age. The lack of hyper-responsiveness of immune cells in these NOD mice (investigating an impressive panel of different leukocyte types and assays) is surprising since hyper-responsiveness had been found in 3 other strains with a knock out of Zbtb32. This raise an important question of whether immune responses and their regulation in NOD mice are different compared to other commonly used mice strains with respect to regulation by Zbtb32. However, as noted and discussed by the authors, the mutation on the NOD background was created using CRISPR/CAS9 whereas the 3 strains where the KO was successful in enhancing immune reactivity were more traditional KO mice. Furthermore the immune reactivity assays in this report are only comparing activation of cells from NOD mice without direct comparison to cells from the other strain backgrounds. As such this question may warrant a more detailed investigation before it can be answered conclusively. The manuscript is clearly written and experimental designs are technically sound.

Is the work clearly and accurately presented and does it cite the current literature? Yes

Is the study design appropriate and is the work technically sound? Yes

Are sufficient details of methods and analysis provided to allow replication by others? Yes

If applicable, is the statistical analysis and its interpretation appropriate? Yes 
Are all the source data underlying the results available to ensure full reproducibility? Yes

Are the conclusions drawn adequately supported by the results?

Yes

Competing Interests: No competing interests were disclosed.

Reviewer Expertise: Autoimmunity of Type 1 Diabetes

I confirm that I have read this submission and believe that I have an appropriate level of expertise to confirm that it is of an acceptable scientific standard.

Reviewer Report 09 April 2018

https://doi.org/10.5256/f1000research.15070.r31946

(c) 2018 Tse H. This is an open access peer review report distributed under the terms of the Creative Commons Attribution License, which permits unrestricted use, distribution, and reproduction in any medium, provided the original work is properly cited.

\section{Hubert M. Tse}

Comprehensive Diabetes Center, Department of Microbiology, School of Medicine, University of Alabama at Birmingham, Birmingham, AL, USA

Defining how tolerance is lost in Type 1 diabetes (T1D) will significantly contribute to our understanding of autoimmune dysregulation and the generation of beta-cell-specific effector $T$ cell responses. Previous studies by the Tarbell lab demonstrated that DCIR2 ${ }^{+}$tolerogenic dendritic cells could promote self-tolerance to autoreactive CD4 T cells partly due to the upregulation of the transcription factor Zbtb32 in CD4 T cells. Overexpression of Zbtb32 in CD4 T cells was effective in delaying T1D by decreasing T cell proliferation and IFN-gamma synthesis. To further confirm the role of Zbtb32 in autoimmune diabetes, the current manuscript by Coley, et al. attempts to test the hypothesis that loss of Zbtb32 will exacerbate diabetogenic $T$ cell responses and accelerate T1D in newly derived NOD.Zbtb32/- mice. Contrary to their hypothesis, the data presented displays a moderate acceleration in spontaneous diabetes in male NOD.Zbtb32 $2^{-/-}$mice, but no difference in female mice. In addition, there were no significant differences observed in activation markers, IFN-gamma synthesis, or proliferation between CD4, CD8, NK, and B cells in NOD and NOD.Zbtb32-/- mice. The manuscript is well-written, results are interesting, and the conclusions are supported by the provided data. While the majority of the data is "negative", the results are insightful and informative to the T1D research community. However, there are minor concerns that need to be addressed with the manuscript in its current form:

1. Zbtb32 is a negative regulator of GATA3, did the authors ever examine GATA3 expression levels and GATA3-dependent signaling pathways to determine if Th2 cytokine responses were elevated in NOD.Zbtb32--mice?

2. The spontaneous incidence of T1D in female mice was stopped at 35 weeks of age, but the 
male incidence stopped at 45 weeks of age, if the female incidence was extended to the same time point, was there a difference?

3. I agree with the authors' discussion concerning strain differences and potential compensatory mutations that may account for the absence of accelerated T1D in NOD.Zbtb32 $2^{-/}$mice in contrast to other inbred mouse models. Out of curiosity, was EAE ever induced in NOD.Zbtb32 $2^{--}$mice to determine if this mouse may exhibit an increased susceptibility to ascending paralysis?

4. The figure legend for 4 needs to be consistent since the symbols are different for NOD and NOD.Zbtb32-/- mice.

Is the work clearly and accurately presented and does it cite the current literature? Yes

Is the study design appropriate and is the work technically sound? Yes

Are sufficient details of methods and analysis provided to allow replication by others? Yes

If applicable, is the statistical analysis and its interpretation appropriate? Yes

Are all the source data underlying the results available to ensure full reproducibility? Yes

Are the conclusions drawn adequately supported by the results?

Yes

Competing Interests: No competing interests were disclosed.

I confirm that I have read this submission and believe that I have an appropriate level of expertise to confirm that it is of an acceptable scientific standard.

Author Response 16 Apr 2018

Kristin Tarbell, National Institute of Diabetes and Digestive and Kidney Diseases, National Institutes of Health, Bethesda, USA

Thank you for taking the time to review our article and for your thoughtful responses. We truly appreciate your review and will endeavor to provide satisfactory responses to each the concerns that you raised.

Query 1) Zbtb32 is a negative regulator of GATA3, did the authors ever examine GATA3 expression levels and GATA3-dependent signaling pathways to determine if Th2 cytokine responses were elevated in NOD.Zbtb32-/- mice?

Answer: It is our understanding that Zbtb32 normally inhibits the function of GATA3 by physically occupying the DNA binding site for GATA3, and not by regulating its gene 
expression. Consequently, we did not examine GATA3 gene expression. We did examine cytokine production in NOD.Zbtb32-/- lymphocytes (see Fig. 4), but did not observe any differences compared to control mice.

Query 2) The spontaneous incidence of T1D in female mice was stopped at 35 weeks of age, but the male incidence stopped at $\mathbf{4 5}$ weeks of age, if the female incidence was extended to the same time point, was there a difference?

Answer: We monitored most of the female mice (50 out of 55) past 35 weeks but did not encounter any cases of disease onset in females beyond 31 weeks. The figure for disease incidence in females was truncated at 35 weeks for the sake of clarity.

Query 3) I agree with the authors' discussion concerning strain differences and potential compensatory mutations that may account for the absence of accelerated T1D in NOD.Zbtb32-/- mice in contrast to other inbred mouse models. Out of curiosity, was EAE ever induced in NOD.Zbtb32-/- mice to determine if this mouse may exhibit an increased susceptibility to ascending paralysis?

Answer: No, we never attempted to induce EAE in the NOD.Zbtb32-/- mice.

Query 4) The figure legend for 4 needs to be consistent since the symbols are different for NOD and NOD.Zbtb32-/- mice.

Answer: Thank you for the feedback. In Figure 4, data is shown for 3 cell types from both wild type and knockout animals. Each cell type was assigned its own symbol, but the coloration is consistent with the genotype. All wildtype data uses black, filled symbols; all knockout data uses open symbols. We will submit a revision to make this more clear to future readers.

Thank you again for your feedback and constructive criticism.

Competing Interests: We have no conflicts to report.

Reviewer Response 17 Apr 2018

Hubert Tse, University of Alabama at Birmingham, Birmingham, USA

Thank you for your responses! I have no other concerns.

Competing Interests: No competing interests were disclosed. 
The benefits of publishing with F1000Research:

- Your article is published within days, with no editorial bias

- You can publish traditional articles, null/negative results, case reports, data notes and more

- The peer review process is transparent and collaborative

- Your article is indexed in PubMed after passing peer review

- Dedicated customer support at every stage

For pre-submission enquiries, contact research@f1000.com 